\title{
The Results of Theoretical and Practical Studies of Flotation of Nanoscale Silicon Structures
}

\author{
Victor V. Kondratyev*, Antonina I. Karlina, \\ Alexander A. Nemarov and Nikita N. Ivanov \\ Irkutsk National Research Technical University \\ 83 Lermontova, Irkutsk, 664074, Russia
}

Received 19.03.2016, received in revised form 20.05.2016, accepted 02.07.2016

This paper presents theoretical calculations and the results of laboratory experiments showing that almost all quartzite, carried away as a fine dust phase in gas removal and gas cleaning, presented spheroidized micro-and nanoparticles of $\mathrm{SiO}_{2}$. It takes the dust of gas purification from the class of "waste" in class "product" if carbon impurities, which invariably accompanies in a fine dust, will be removed.

As a result of studying the properties of the dust production of silicon revealed that $85 \%$ of it represented with spheroidized particles of $\mathrm{SiO}_{2}$, and the resulting amounts of dust makes a promising source for production. The best process for extracting the associated carbon nanotubes is flotation. Floating particles of micro and nano-sized particles should be carried out in a laminar flow of the pulp with the fewest basic flotation cycles. In the thick layer of watery foam microspheres and nanospheres of silica are washed away in the chamber of the product interbubble channels. Flotation air bubbles should be nano and micro size. Initial bubbles emerging from the aerator must be close to monodisperse distribution. The reagents used need to be more soluble in water than conventional. As the aerator should be used pneumohydraulic aerator. To activate hydrophilized particles of valuable component need to use pressure flotation. To reduce energy consumption and time of flotation need the smallest number of elementary cycles of flotation (ETSF). Before and after the flotation conglomerates of valuable component particles with other particles should be broken, as well as to make the necessary removal of impurities of the sand slurry. The results demonstrated that as a co-product along with the metallurgical silicon is formed a large amount of dust containing up to $85 \%$ of spheroidized micro-and nanoparticles of silicon dioxide and up to $10 \%$ carbon nanotube content and other nanoparticles. Enrichment product possible to $99.5 \%$. Further enrichment requires additional research.

Keywords: silica, flotation, nanostructures, aeration, crystalline phase, thermodynamics, fluctuation, crystallization.

Citation: Kondratyev V.V., Karlina A.I., Nemarov A.A., Ivanov N.N. The results of theoretical and practical studies of flotation of nanoscale silicon structures, J. Sib. Fed. Univ. Eng. technol., 2016, 9(5), 656-668. DOI: 10.17516/1999-494X2016-9-5-657-670.

(C) Siberian Federal University. All rights reserved

* Corresponding author E-mail address: kvv@istu.edu 


\title{
Результаты теоретических
}

\section{и практических исследований флотации наноразмерных кремнийсодержащих структур}

\author{
В.В. Кондратьев, А.И. Карлина, \\ А.А. Немаров, Н.Н. Иванов \\ Иркутский национальный \\ исследовательский технический университет \\ Россия, 664074, Иркутск, Лермонтова, 83
}

Изложены теоретические расчеты и результаты лабораторных экспериментов, свидетельствуюшче о том, что практически весь кваричит, уносимый в виде тонкой пылевой фазы в систему газоудаления и газоочистки, представлен сфероидизированными микро- и наночастицами $\mathrm{SiO}_{2}$. Это переводит пыль газоочистки из класса «отход» в класс «продукт» при условии удаления примеси углерода, которая неизменно сопутствует также в виде тонкодисперсной пыли.

В результате изучения свойств пыли производства кремния выявлено, что на 85 \% она представлена сфероидизированными частицами $\mathrm{SiO}_{2}$, а образующиеся объемы делают пыль перспективным источником для производства продукиии. Оптимальнылм процессом для попутного извлечения углеродных нанотрубок является флотация. Флотацию частиц наноразмерных и микроразмерных частиц следует осуществлять в ламинарном потоке пульпы с наименьиим количеством элементарных ичиклов флотации. В толстом слое обводненной пены микросферы, наносферы и наношарики кремнезема смываются в камерный продукт по межпузырьковым каналам. Флотационные пузырьки воздуха должны быть нано- и микрокрупности. Исходные пузырьки, выходящче из аэратора, должны быть близки к монодисперсному распределению. Используемые реагенты должны быть более растворимые в воде, чем традиционные. В качестве аэратора следует использовать пневмогидравлический аэратор. Для активации гидрофилизированных частиц ценного компонента нужно применять напорную флотацию. Для снижения энергозатрат и времени флотации необходимо наименьшее количество элементарных цчиклов флотации (ЭЦФ). Перед флотацией и после нее следует разбивать конгломераты частиц цуенного компонента с другими частицами, а также производить необходимую очистку от примесей и песковой части илама.

В результате исследований выявлено, что в качестве попутного продукта наряду с металлургическим кремнием образуется большое количество пьли, содержащей до $85 \%$ сфероидизированных микро- и наночастиц диоксида кремния и до $10 \%$ углерода с содержанием нанотрубок и других наночастиц. Обогащение продукта возможно до 99,5 \%. Дальнейшее обогащцение требует дополнительных исследований.

Ключевые слова: кремнезем, флотация, наноструктуры, аэрация, кристаллическая фаза, термодинамика, флуктуация, кристаллизация.

\section{Введение}

В настоящее время одной из основных задач является снижение себестоимости продукции в первую очередь за счет снижения энергопотребления и вовлечения в технологические процессы попутных продуктов или отходов. Развитие науки и техники уже на данном этапе позволяют большую часть отходов превращать в полезную продукцию, снижая издержки и улучшая экологическую ситуации в промышленных районах. 
Производство кремния характерно «похожестью» процессов с технологической схемой производства сфероидизированных кварцевых гранул - начиная с сырья, заканчивая высокотемпературными процессами.

В связи с тем, что теоретические расчеты и результаты лабораторных экспериментов свидетельствуют о том, что практически весь кварцит, уносимый в виде тонкой пылевой фазы в систему газоудаления и газоочистки, представлен сфероидизированными микро- и наночастицами $\mathrm{SiO}_{2}$, это переводит пыль газоочистки из класса «отход» в класс «продукт» при условии удаления примеси углерода, которая неизменно сопутствует также в виде тонкодисперсной пыли [1-12].

В данной статье представлены результаты теоретических расчетов, лабораторных испытаний, изучения свойств пыли кремниевого производства, обзор существующих способов улавливания, а также результаты исследований по флотационному разделению полезных компонентов.

В наших опытах были испытаны несколько вариантов флотационного разделения частиц шлама: кипячение, флотация в перекиси водорода, флотация в стандартной механической флотомашине, флотация в разработанной нами лабораторной флотомашине.

\section{Флотация кипячением}

В эксперименте взято исходного сухого шлама 151,3 г. Добавлено 600 мл воды, 5 г керосин и 15 г жидкого стекла. Проводилось слабое кипячение в течение 1,5 ч в литровом стеклянном стакане. Были получены следующие результаты (табл. 1).

Пробы содержали еще ряд примесей, каждой из которых было меньше $1 \%$.

По результатам данного эксперимента видно, что при длительном кипячении наночастицы шлама можно разделить, но для этого потребуются значительные энергетические затраты. Меньшее содержание углерода и большее содержание кремния в верхнем слое объясняются следующими факторами.

Во-первых, в верхний слой всплывали сферы кремнезема, имеющие меньшую плотность, чем плотность пульпы.

Во-вторых, конгломераты углеродных частиц и кремнезема имеют значительное отношение их поверхности к их объему, что приводит к их выносу в верхнюю часть сосуда.

B-третьих, при кипячении и обычной флотации даже существенно гидрофилизированные наночастицы $\mathrm{SiO}_{2}$ за счет пленочной флотации переходят в пенный продукт.

Таблица 1. Результаты флотации кипячением

\begin{tabular}{|l|c|c|c|c|}
\hline \multicolumn{1}{|c|}{ Проба } & \multicolumn{4}{c|}{ Содержание, \% } \\
\cline { 2 - 5 } & $\mathrm{O}$ & $\mathrm{C}$ & $\mathrm{Si}$ & $\mathrm{Na}$ \\
\hline 1-я проба верхнего слоя пульпы стакана & 33 & 59 & 5,9 & 1,33 \\
\hline 2-я проба верхнего слоя пульпы стакана & 36,7 & 53 & 7,5 & 1,7 \\
\hline 3-я проба слоя пульпы со средней части стакана & 21,5 & 67 & 2,4 & 5,44 \\
\hline 4-я проба слоя пульпы со средней части стакана & 22 & 64 & 0,74 & 5 \\
\hline
\end{tabular}


Это объясняется тем, что гравитационные и гидростатические силы пропорциональны кубу диаметра частицы, а поверхностные силы пропорциональны диаметру частицы. Поэтому из простых расчетов видно, что поверхностные силы даже для существенно гидрофильных наночастиц $\mathrm{SiO}_{2}$ значительно превышают гравитационные и гидростатические. Без потери общности краевой угол смачивания $\alpha$ можно рассчитать для цилиндра $\mathrm{SiO}_{2}$, закрепившегося на поверхности раздела фаз воздух-вода, с радиусом $r$ и высотой $2 r$ (рис. 1).

Получаем:

$$
\begin{aligned}
& F_{2}-F_{a}=2 \pi r^{3}\left(\rho_{\text {SiO }_{2}}-\rho_{\mathrm{H}_{2} 0}\right) \cdot g=2 \cdot 3,14 \cdot 10^{-21} \cdot 1600 \cdot 10=1,00531 \cdot 10^{-16} \mathrm{H} \\
& F_{n . H}=\sigma \cdot 2 \pi \cdot r=72 \cdot 10^{-3} \cdot 2 \cdot 3,14 \cdot 10^{-7}=4,52 \cdot 10^{-8} \mathrm{H} \\
& \sin \alpha=\frac{F_{2}-F_{a}}{F_{n . H}}=\frac{1,00531 \cdot 10^{-16}}{4,52 \cdot 10^{-8}}=2,22222 \cdot 10^{-9} \\
& \alpha=\arcsin (\sin \alpha)=2,22222 \cdot 10^{-9},
\end{aligned}
$$

где $F_{2}$ - вес цилиндра $\mathrm{SiO}_{2} ; F_{a}$ - сила Архимеда; $F_{n . н .}$ - сила поверхностного натяжения; $\rho_{\mathrm{SiO}_{2}}=2600 \kappa 2 / \mathrm{M}^{3}$ - плотность $\mathrm{SiO}_{2} ; \rho_{\text {H2O }}=1000 \kappa 2 / \mathrm{M}^{3}$ - плотность воды; $r=10^{-7} \mathrm{M}-$ радиус шарика; $\sigma=72 \cdot 10^{-3} \mathrm{H} / \mathrm{M}-$ поверхностное натяжение на разделе фаз воздух-вода; ускорение свободного падения $g$ возьмём $=10 \mathrm{M} / \mathrm{c}^{2}$.

Следовательно, при обычном дисперсном составе исходных пузырьков при флотации крупность пузырьков значительно больше гидрофильных наночастиц. Эти частицы хорошо флотируются на пузырьках, размер которых значительно превышает размер наночастиц, за счет пленочной флотации.

На фотографиях (рис. 2), сделанных под электронным микроскопом, хорошо видны засохшие пузырьки микронных размеров, облепленные наношариками $\mathrm{SiO}_{2}$. Общеизвестно, что краевой угол смачивания кварца составляет от 0 до $10^{\circ}$.

Таким образом, при $\alpha$ незначительно больше нуля наночастицы кварца будут легко флотироваться. Исходя из этого, флотацию наноразмерных частиц следует осуществлять соразмерными с ними пузырьками [13-16].

Применение не растворимых в воде пенообразователей способствует образованию комплекса (микро- и нанокапелек, пузырьков и гидрофильных наночастиц), который также хорошо переходит в пенный продукт.

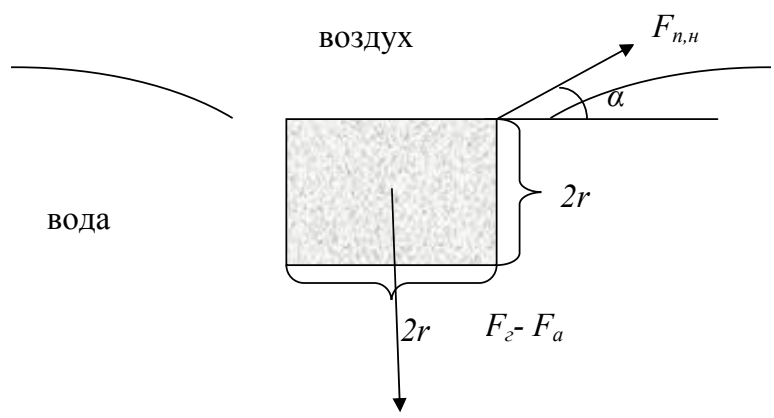

Рис. 1. Схема закрепившейся минеральной частицы на разделе фаз вода-воздух при пленочной флотации 


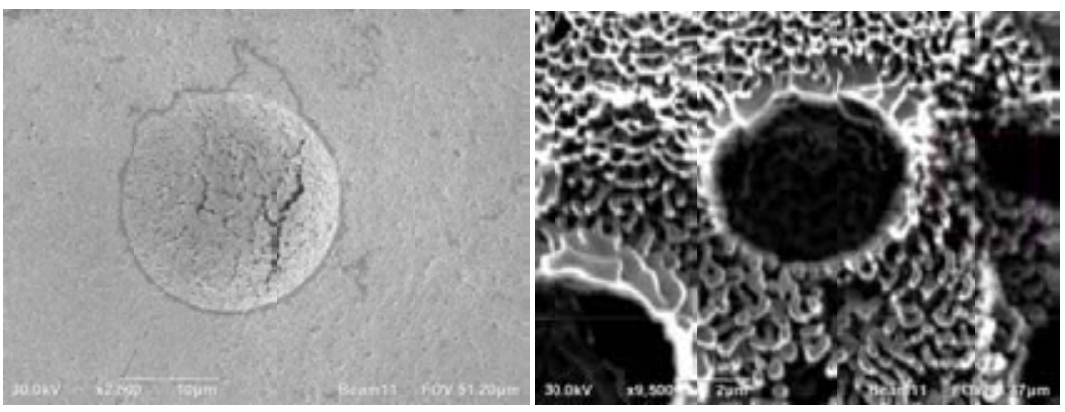

Рис. 2. Высохшие пузырьки воздуха с закрепившимися на них наношариками кремнезема

Применение собирателей (например, аполярных реагентов) также способствует образованию комплекса, который легко флотируется.

Углеродные частицы и наношарики $\mathrm{SiO}_{2}$ образуют сростки, имеющие большое отношение поверхности сростка к его объему, что способствует переходу такого сростка в пенный продукт.

Примеси солей и другие примеси образуют с наношариками сростки, которые также увеличивают отношение поверхности сростка к его объему, что приводит к выходу его в пенный продукт [16-18].

Образование флотокомплекса при обычной флотации весьма мала, так как крупные пузырьки воздуха, движущиеся в объеме пульпы с большой скоростью по сравнению со скоростью наночастицы, с меньшей вероятностью образуют необходимый флотокомплекс.

Углерод, содержащийся в исходном шламе, имеет плотность $1,7 \mathrm{r}_{\mathrm{cm}}^{2}$. Плотность $\mathrm{SiO}_{2}=2,6$ г $/ \mathrm{cm}^{2}$. Данную разность плотностей и различие в гидрофобности данных частиц следует использовать при их разделении во флотомашине. В пенном слое, в котором скорость воды по межпузырьковым каналам больше нескольких миллиметров в секунду, пузырьки, нагруженные частицами $\mathrm{SiO}_{2}$, легко смываются в подпенный слой. В то же время углеродные частицы, имеющие более гидрофобную поверхность и большое отношение поверхности к объему, застревают в межпузырьковых каналах пены. Следовательно, для разделения данных частиц шлама нужно создавать достаточно толстый слой пены, содержащий мелкие пузырьки, близкие по объему с частицами $[19,20]$.

Из результатов вышеприведенных экспериментов следует вывод, что с помощью пневмогидравлического аэратора можно получать мелкие и одинаковые но крупности пузырьки, способствующие повышенной устойчивости аэрированной жидкости (пены) и, следовательно, снижению расхода пенообразователя.

\section{Флотация в перекиси водорода}

5 г исходного шлама перемешивали с 1 мл бутилового спирта и 20 мл воды. Полученную смесь обрабатывали ультразвуковым (частота 26,5 кГц) аппаратом УРСК 7-Н-22 в течение 10 мин.

Затем в полученную суспензию добавляли 1 мл $3 \%$-ной перекиси водорода. Были взяты четыре образца высохшего пенного слоя. Анализ образцов отражен в табл. 2. 
Таблица 2. Анализ отфлотированных образцов

\begin{tabular}{|c|c|c|c|}
\hline \multirow{2}{*}{ Номер образца } & \multicolumn{3}{|c|}{ Содержание элементов, \% } \\
\cline { 2 - 4 } & $\mathrm{O}$ & $\mathrm{C}$ & $\mathrm{Si}$ \\
\hline 1 & 17,2 & 80,4 & 1,12 \\
\hline 2 & 9,76 & 89,02 & 0,58 \\
\hline 3 & 11,9 & 86,28 & 1,17 \\
\hline 4 & 9,67 & 89,01 & 0,74 \\
\hline
\end{tabular}

Достаточно хороший результат объясняется тем, что перекись водорода дает достаточно мелкие пузырьки, которые не создают турбулентных потоков жидкости и образуют с бутанолом толстый слой пены, способствующей существенному разделению частиц углерода и кремнезема. Недостатки данного способа: медленное разделение частиц (флотация продолжалась несколько часов), большой расход перекиси водорода.

\section{Флотация в механической лабораторной машине}

Для первоначальной флотации была выбрана стандартная лабораторная флотомашина с объемом камеры 1 дм³.

Данная конструкция не позволяет разделить наночастицы углерода и кремнезема, так как предназначена для флотации более крупных минеральных частиц. Импеллер такой флотомашины создает турбулентный поток пульпы, который выносит практически все частицы в пенный продукт.

Во флотомашине возникает полидисперсная система пузырьков с множеством пузырьков большой крупности, выносящих на поверхность пены гидрофильные и гидрофобные наночастицы. Частицы в данной камере проходят очень короткий путь, за который они не успевают разделиться должным образом.

Наночастицы плохо разделяются и из-за образованного в камере пенного слоя, имеющего небольшую высоту и длину. Содержание углерода в пенном продукте после нескольких флотаций составило 25-30 \%, что немногим более содержания в исходном шламе.

Разумеется, можно поставить большой ряд таких флотомашин и постепенно поднять извлечение, но это существенные энергетические, технологические и конструктивные затраты. В такой цепочке флотомашин появляются условия значительного множества элементарных циклов флотации (ЭЦФ), т.е. флотокомплексы создаются, всплывают, разрушаются, тонут и вновь создаются, - это происходит много раз. И на каждый ЭЦФ требуются определенные затраты энергии.

Из вышеприведенных экспериментов видно, что флотация наночастиц и микрочастиц должна отличаться от стандартной технологии. Поэтому были разработаны два варианта лабораторной флотомашины с применением пневмогидравлического аэратора.

Аэратор выполнял три функции: первоначальную подачу пульпы в объем камеры, диспергацию воздушных пузырей в пульпе и подачу эмульсии (тумана) пенообразователя в камеру флотомашины [13-15, 21, 22]. 
С помощью аэратора при подборе концентрации пенообразователя от 20 до 150 мг на 1 дм³ пульпы предварительно создавался такой режим работы 4-камерной флотомашины, при котором в первой камере перечистки образовывался пенный слой толщиной около 1 см, во второй - больший слой пены, в третьей - еще больший и в четвертой - более $3 \mathrm{~cm}$.

В результате производилась сепарация пузырьков по крупности в данных камерах перечистки: в первой, имеющей больший объем, присутствовали пузырьки наибольшей крупности, во второй - меньшей крупности, в третьей - меньшей крупности, чем во второй, в четвертой меньшей крупности, чем в третьей. В 3-камерной флотомашине пенный слой в 3-й камере составлял 10-15 см.

Следует особо отметить, что для осуществления элементарного акта флотации производилась обработка пульпы через эжектор (аэратор). Во-первых, при прохождении пульпы через зону разряжения в аэраторе происходит выделение растворенного газа на гидрофобных участках шлама (напорная флотация), во-вторых, в аэраторе в замкнутом объеме имеет место наибольшая вероятность контакта частиц с пузырьками воздуха.

В одном из первых флотационных экспериментов производилась флотация измельчённого влажного шлама (766 г), просушенного при $\mathrm{t}=200{ }^{\circ} \mathrm{C}$ в печи. В высушенный шлам (604 г) было добавлено 20 г керосина и 20 г жидкого стекла.

Полученный материал еще раз измельчался на дисковом истирателе до получения гомогенного продукта (меньше 1 мкм). В лабораторной 20-литровой 4-камерной флотомашине проводилось кондиционирование материала в течение 10 мин, затем производилась флотация.

В качестве пенообразователя использовали сосновое масло $(100$ мг/дм³ $)$. Пенный слой в камере перед сливным порогом флотомашины составлял в начале около 7 см, а в конце - около 2 см. Результаты эксперимента приведены в табл. 3.

Содержание элементов в полученных продуктах практически не изменилось по сравнению с исходным шламом. Это можно объяснить, скорее всего, тем, что в просушенном шламе все частицы достаточно гидрофобны, чтобы сфлотироваться в пенный продукт.

Для депрессии частиц двуокиси кремния необходимо большее время кондиционирования (лучше пропарка с жидким стеклом), при котором за счет жидкого стекла произойдет их гидрофилизация.

В следующих флотационных экспериментах производилась флотация шлама (2 кг) при

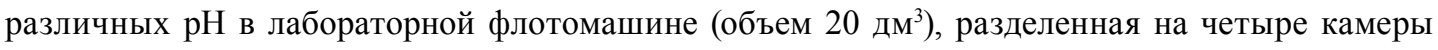
перечистки (I, II, III, IV). В качестве собирателя был выбран керосин (2,5 мг/дм³).

Таблица 3. Результаты флотации с сосновым маслом

\begin{tabular}{|c|c|c|c|}
\hline \multirow{2}{*}{ Наименование продукта } & \multicolumn{3}{|c|}{ Содержание элементов, \% } \\
\cline { 2 - 4 } & $\mathrm{O}$ & $\mathrm{C}$ & $\mathrm{Si}$ \\
\hline Пенный продукт & 60,25 & 20,85 & 17,3 \\
\hline Камерный продукт & 62 & 15,8 & 19,7 \\
\hline
\end{tabular}

$$
-663-
$$


Пенообразователь - сосновое масло (100 мг/дм³). Аэрация пульпы производилась пневмогидравлическим аэратором-эжектором. Воздух подсасывался в аэратор струёй пульпы из атмосферы.

Пульпа закачивалась из I-й камеры перечистки и подавалась насосом в аэратор. Давление закачиваемой пульпы составляло 0,4 МПа.

При $\mathrm{pH}=6$ в пенном продукте содержание углерода, кремния и кислорода практически не изменялось по сравнению с исходным шламом, подаваемым во флотомашину. При $\mathrm{pH}=9,5$ происходило разделение частиц двуокиси кремния и углерода. Время флотации 30 мин.

Следующие флотационные эксперименты проводились после кондиционирования (время кондиционирования от 0,5 до 1,5 ч) влажного шлама (около 10 кг) с керосином (2,5 мг на 1 дм

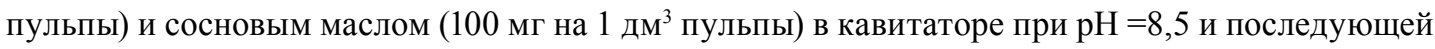
флотации в 4-камерной флотомашине. Шлам перед кондиционированием освобождался от песковой части (мелкие кристаллы кварца, карбида кремния и др.). При прочих равных условиях были получены следующие данные для камерного и пенного продуктов в зависимости от высоты пенного слоя в 4-й камере флотомашины перед сливным порогом. Результаты приведены в табл. 4.

В то же время частицы углерода, имеющие развитую гидрофобную поверхность и большое отношение поверхности к объему (рис. 3), хорошо закреплялись на пузырьках, в межпузырьковых каналах и образовывали флотируемые аэрофлокулы, что в дальнейшем способствовало их выходу в пенный продукт.

Таблица 4. Содержание элементов от высоты пенного слоя в 4-й камере флотомашины

\begin{tabular}{|c|c|c|c|c|c|}
\hline \multirow{2}{*}{ № } & \multirow{2}{*}{$\begin{array}{c}\text { Высота пенного } \\
\text { слоя, см }\end{array}$} & \multirow{2}{*}{ Пенный и камерный продукты } & \multicolumn{3}{|c|}{ Содержание элементов, \% } \\
\hline & & & $\mathrm{C}$ & $\mathrm{O}$ & $\mathrm{Si}$ \\
\hline \multirow{2}{*}{1} & \multirow{2}{*}{$1 \pm 0,5$} & Пенный & 33,7 & 50 & 15,6 \\
\hline & & Камерный & 6,6 & 66 & 26 \\
\hline \multirow{2}{*}{2} & \multirow{2}{*}{$3 \pm 0,5$} & Пенный & 46,3 & 42,7 & 10,3 \\
\hline & & Камерный & 5,4 & 70 & 21,5 \\
\hline \multirow{2}{*}{3} & \multirow{2}{*}{$5 \pm 1$} & Пенный & 45,2 & 40,4 & 11,4 \\
\hline & & Камерный & 7 & 68,2 & 23,5 \\
\hline \multirow{2}{*}{4} & \multirow{2}{*}{$8 \pm 2$} & Пенный & 63 & 29 & 7,5 \\
\hline & & Камерный & 9 & 63 & 26,6 \\
\hline \multirow{2}{*}{5} & \multirow{2}{*}{$10 \pm 3$} & Пенный & 58 & 30 & 8,5 \\
\hline & & Камерный & 10,5 & 58 & 30,1 \\
\hline \multirow{2}{*}{6} & \multirow{2}{*}{$10 \pm 3$} & $\begin{array}{l}\text { Пенный после двойной перечистки } 60 \text { \% } \\
\text { (углерод) пенного продукта предыдущих } \\
\text { флотаций }\end{array}$ & 82 & 10 & 4,4 \\
\hline & & $\begin{array}{l}\text { Камерный после двойной перечистки } 60 \text { \% } \\
\text { (углерод) пенного продукта предыдущих } \\
\text { флотаций }\end{array}$ & 6,63 & 67,67 & 24,72 \\
\hline \multirow{2}{*}{7} & \multirow{2}{*}{$9-15$} & Пенный & 86 & 12 & 0,8 \\
\hline & & Камерный & 7,63 & 65,67 & 25,3 \\
\hline
\end{tabular}



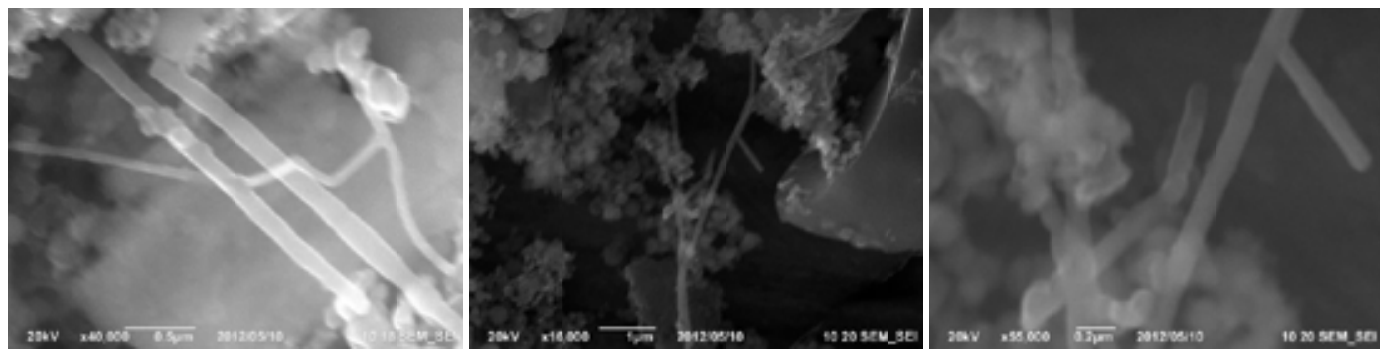

Рис. 3. Пенный продукт

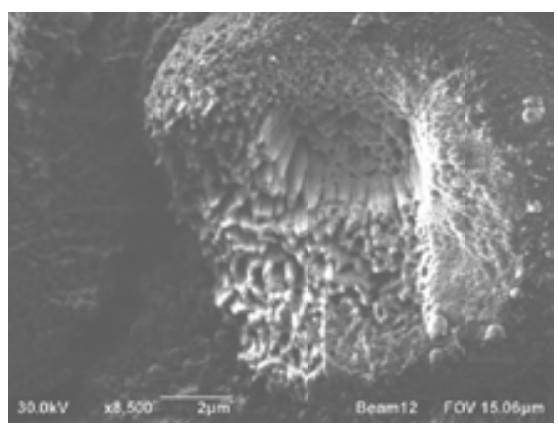

Рис. 4. Пенный продукт (конгломераты углеродных нанотрубок - 97 \% углерода)

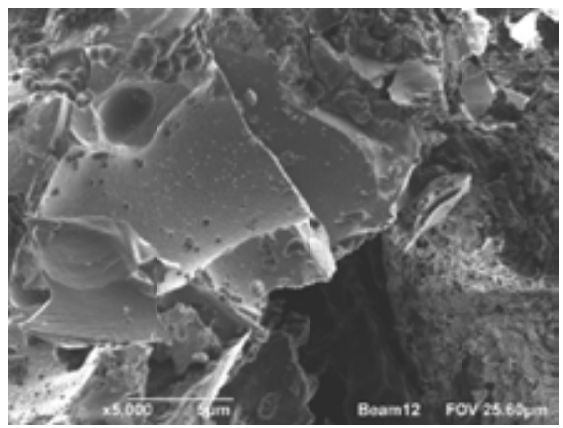

Рис. 6. Пенный продукт (конгломераты углеродных частиц)

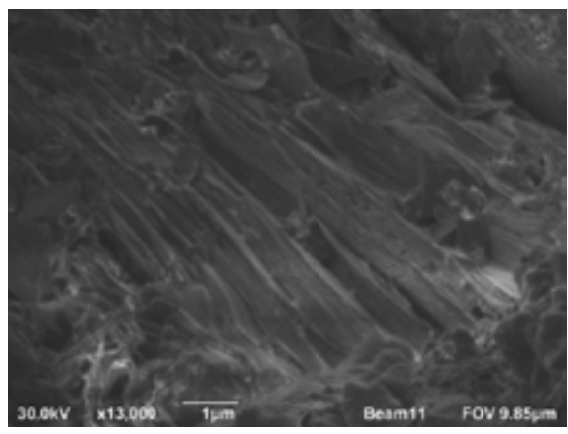

Рис. 5. Пенный продукт (конгломераты углеродных нанотрубок - 95 \% углерода)

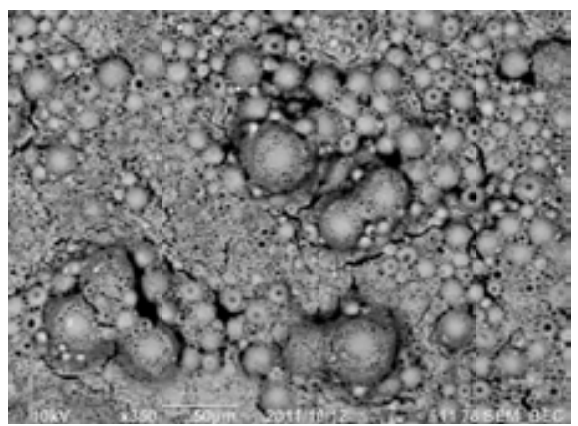

Рис. 7. Микросферы и наносферы после обработки в кавитаторе

На рис. 4-6 приведены изображения пенного продукта - концентрата углеродных нанотрубок.

На рис. 7-10 изображены промежуточные и сопутствующие продукты.

На рис. 11 приведены изображения сфероидизированных нано- и микрочастиц диоксида кремния.

Исходя из полученных результатов флотации в 4-камерной лабораторной флотомашине, геометрия флотомашины была несколько изменена, чтобы исключить ряд негативных факторов: 
- в 4-камерной флотомашине элементарных циклов флотации достаточно много (создание флотокомплекса, подъем его в пенный слой и затем его разрушение происходит много раз), что сильно снижает скорость флотации и увеличивает энергозатраты;

- толстый пенный слой в многокамерной флотомашине сложнее получить;

- гидродинамика флотомашины не позволяет получить требуемую дисперсную систему пузырьков воздуха в последней камере перечистки перед сливным порогом.

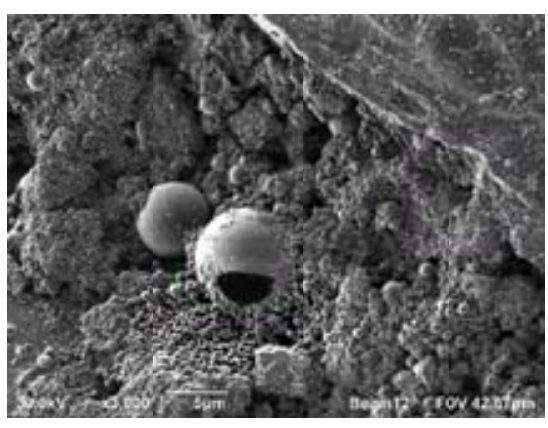

Рис. 8. Исходный шлам с микросферами (на переднем плане видна микросфера, разрезанная ионным пучком)

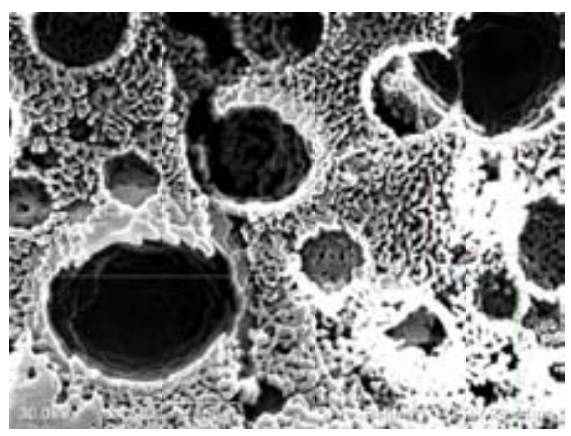

Рис. 9. Засохшие пузырьки, покрытые наношариками кремнезема, полученные при флотации в тонком слое пены

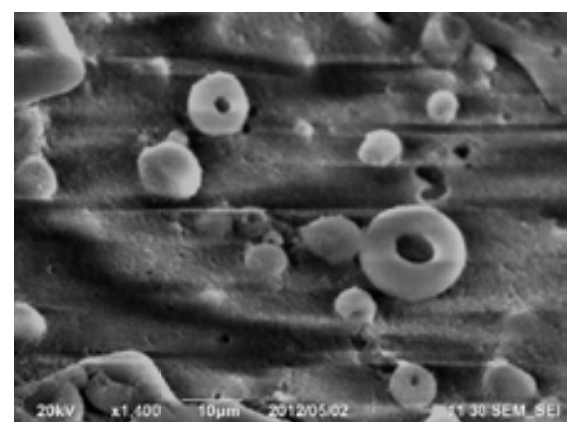

Рис. 10. Торроидальные структуры кремнезема пенного продукта, отожженного при $500^{\circ} \mathrm{C}$
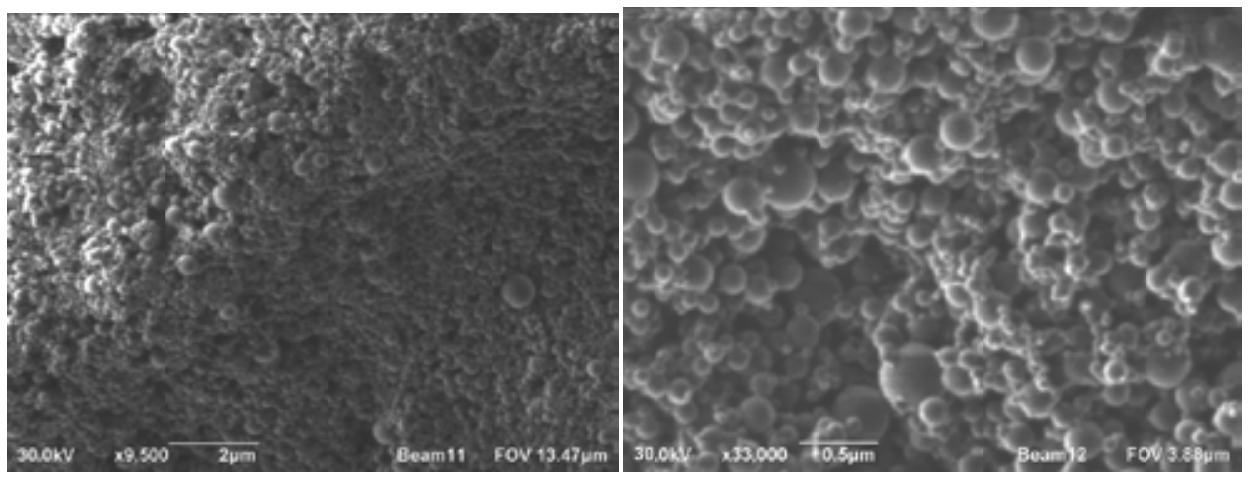

Рис. 11. Камерный продукт (наношарики кремнезема) 
Трехкамерная флотомашина позволила создать пенный слой более 15 см, и в результате в пенном продукте содержание углерода составило при ряде флотационных экспериментов от 96 до $97 \%$, а кремния - от 1,3 до 1,7 \%. В то же время содержание кремнезема в камерном продукте - от 96 до 97 \%, а углерода - от 1,5 до 2,5 \%. С данным содержанием компонентов было получено около 20 кг пенного продукта и около 30 кг камерного продукта [20-24].

Резюмируя результаты экспериментов по флотации, можно сделать следующие выводы.

Флотацию частиц наноразмерных и микроразмерных частиц следует осуществлять в ламинарном потоке пульпы с наименьшим количеством элементарных циклов флотации.

Пенный слой пенной сепарации частиц должен быть как можно больше (как минимум, больше 3 см). В толстом слое обводненной пены микросферы, наносферы и наношарики кремнезема смываются в камерный продукт по межпузырьковым каналам.

Флотационные пузырьки воздуха должны быть нано- и микрокрупности.

Исходные пузырьки, выходящие из аэратора, должны быть близки к монодисперсному распределению.

Используемые реагенты (пенообразователи, собиратели) должны быть более растворимые в воде, чем традиционные.

Плохорастворимые реагенты следует разбивать в монодисперсную эмульсию наночастиц реагента.

В качестве аэратора следует использовать пневмогидравлический аэратор.

Статья подготовлена с использованием результатов работ, выполненных в ходе проекта 02.G25.31.0174 «Разработка комплексной ресурсосберегающей технологии и организация высокотехнологичного производства наноструктур на основе углерода и диоксида кремния для улучшения свойств строительных и конструкционныхматериалов» в рамках Программы реализации комплексных проектов по созданию высокотехнологичного производства, утвержденных постановлением Правительства РФ № 218 от 9 апреля 2010 2.

\section{Выводы}

Теоретические расчеты и результаты лабораторных экспериментов свидетельствуют о том, что практически весь кварцит, уносимый в виде тонкой пылевой фазы в систему газоудаления и газоочистки, представлен сфероидизированными микро- и наночастицами $\mathrm{SiO}_{2}$. Это переводит пыль газоочистки из класса «отход»в класс «продукт» при условии удаления примеси углерода, которая неизменно сопутствует также в виде тонкодисперсной пыли.

В результате изучения свойств пыли производства кремния выявлено, что на 85 \% она представлена сфероидизированными частицами $\mathrm{SiO}_{2}$, а образующиеся объемы делают пыль перспективным источником для производства продукции. Оптимальным процессом для попутного извлечения углеродных нанотрубок является флотация.

Флотацию частиц наноразмерных и микроразмерных частиц следует осуществлять в ламинарном потоке пульпы с наименьшим количеством элементарных циклов флотации.

В толстом слое обводненной пены микросферы, наносферы и наношарики кремнезема смываются в камерный продукт по межпузырьковым каналам. Флотационные пузырьки воз-

$$
-667-
$$


духа должны быть нано- и микрокрупности. Исходные пузырьки, выходящие из аэратора, должны быть близки к монодисперсному распределению. Используемые реагенты должны быть более растворимые в воде, чем традиционные. В качестве аэратора следует использовать пневмогидравлический аэратор. Для активации гидрофилизированных частиц ценного компонента нужно применять напорную флотацию. Для снижения энергозатрат и времени флотации конструкция флотомашины должна быть такой, чтобы в ней происходило наименьшее количество элементарных циклов флотации (ЭЦФ). Перед флотацией и после нее следует разбивать конгломераты частиц ценного компонента с другими частицами, а также производить необходимую очистку от примесей и песковой части шлама.

В результате исследований выявлено, что в качестве попутного продукта наряду с металлургическим кремнием образуется большое количество пыли, содержащей до 85 \% сфероидизированных микро- и наночастиц диоксида кремния и до $10 \%$ углерода с содержанием нанотрубок и других наночастиц. Обогащение продукта возможно до 99,5 \%.

\section{Список литературы}

[1] Ростовцев С.Т., Костелов О.Л., Ашин А.К., Анкудинов Р.В. Исследование кинетики взаимодействия в системе Si-O-С. Изв. АН СССР. Металль, 1972, 5, 53-59 [Rostovtsev S.T., Kostelov O.L., Ashin A.K., Ankudinov R.V. Study of kinetics of interaction in the system Si-O-C. Izvestiia AN SSSR. Metally, 1972, 5, 53-59 (in Russian)]

[2] Зельберг Б.И., Черных А.Е., Елкин К.С. Шихта для электротермического производства кремния. Челябинск: Металл, 1994, 330 c. [Zelberg B.I., Chernykh A.E., Elkin K.S. Charge for electrothermal production of silicon. Cheliabinsk, Metall, 1994, 330 p. (in Russian)]

[3] Юдин Б.Ф., Борисов В.Г. Термодинамический анализ диссоциативного испарения карбида кремния. Огнеупоры, 1967, 8, 44-50 [Iudin B.F., Borisov V.G. Thermodynamic analysis of the dissociative evaporation of silicon carbide. Ogneupory, 1967, 8, 44-50 (in Russian)]

[4] Гельд П.В. Высокотемпературные проиессы восстановления. М.: Металлургиздат, 1951 [Geld P.V. High temperature recovery processes. Moscow, Metallurgisdat, 1951 (in Russian)]

[5] Бардин И.П., Щедрин В.М. Восстановление кремния углеродом при переменном давлении газовой фазы. Изв. АН СССР. ОТН, 1957, 11, 27-43 [Bardin I.P., Shchedrin V.M. Recovery of silicon carbon with varying pressure of the gas phase. Izvestiia AN SSSR. OTN, 1957, 11, 27-43 (in Russian)]

[6] Кравченко В.А., Литвинова Т.Н., Левитин В.В. и др. Исследование механизма реакций в системе Si-O-С. Механизм и кинетика восстановления металлов. М.: Наука, 1970, с. 165-177 [Kravchenko V.A., Litvinova T.N., Levitin V.V. et al. Investigation of the mechanism of reactions in the system Si-O-C. The mechanism and kinetics of recovery of metals. Moscow, Nauka, 1970, p. 165-177 (in Russian)]

[7] Кравченко В.А., Литвиненко А.И., Литвинова Т.И. и др. Исследование фазовых и структурных превращений при производстве ферросиликокальция углевосстановительным процессом. Новые методы исследования процессов восстановления черных металлов. М.: Наука, 1974, c. 48-54 [Kravchenko V.A., Litvinenko A.I., Litvinova T.N. et al. The study of phase and structural transformations in the production of ferrosilicone prevostianus process. New methods of research of processes of recovery of ferrous metals. Moscow, Nauka, 1974, p. 48-54 (in Russian)]

$$
-668-
$$


[8] Кравченко В.А., Папин Г.Г., Литвинова Т.И. Исследование процесса образования карбида кремния при пониженном давлении. Абразивы и материалы, 1966, 5, 128-130 [Kravchenko V.A., Papin G.G., Litvinova T.N. The research of the formation of silicon carbide under reduced pressure. Abrazivy i materialy, 1966, 5, 128-130 (in Russian)]

[9] Ашин А.К., Анкудинов Р.В., Костелов О.Л., Ростовцев С.Т. Условия фазовых равновесий Si-O-С. Металлургия и коксохимия. Киев: Техника, 1975, 43, 46-52 [Ashin A.K., Ankudinov R.V., Kostelov O.L., Rostovtsev S.T. Conditions of phase equilibria of Si-O-C. Metallurgiia I koksokhimiia. Kiev, Tekhnika, 43, 46-52 (in Russian)]

[10] Хитрик С.И., Емлин Б.И., Гасик М.И. и др. Восстановление окислов кремния и алюминия углеродом из высокоглиноземистых материалов. Механизм и кинетика восстановления металлов. М.: Наука, 1970, c.178-186 [Khitrik S.I., Emlin B.I., Gasik M.I. Recovery of oxides of silicon and aluminum, with carbon from high-alumina materials. The mechanism and kinetics of recovery of metals. Moscow, Nauka, 1970, c.178-186 (in Russian)]

[11] Катков О.М., Нуйкин Ю.Л., Карпов И.К. Исследование механизма восстановления оксидов кремния с помощью моделирования процесса на ЭВМ. Изв. вузов. Цветная металлургия, 1984, 3, 65-70 [Katkov O.M., Nuikin Iu.L., Karpov I.K. Investigation of the mechanism of recovery of oxides of silicon using process simulation on a computer. Izvestiya Vuzov. Tsvetnaya Metallurgiya (Universities' Proceedings. Nonferrous Metallurgy), 1984, 3, 65-70 (in Russian)]

[12] Рубинштейн Ю.Б., Мелик-Гайказян В.И., Матвеенко Н.В., Леонов С.Б. Пенная сепарация и колонная флотация. М.: Недра, 1989, 304 с. [Rubinshtein Iu.B., Melik-Gaikazian V.I., Matveenko N.V., Leonov S.B. Foam separation and column flotation. Moscow, Nedra, 1989, 304 c. (in Russian)]

[13] Злобин М.Н., Пермяков Г.П., Немаров А.А., Мецик В.М., Медецкий Ю.В., Тарабан H.T. A.c. 1785127 (1987). Б. И., 1995 [Zlobin M.N., Permiakov G.P., Nemarov A.A., Metsik V.M., Medetskii Iu.V., Taraban N.T. Patent 1785127 (1987). B.I., 1995 (in Russian)]

[14] Злобин М.Н., Пермяков Г.П., Немаров А.А., Мецик В.М., Тарабан Н.Т. А.c. 1734860 (1987). Б.И., 1992 [Zlobin M.N., Permiakov G.P., Nemarov A.A., Metsik V.M., Taraban N.T. Patent 1734860 (1987). B.I., 1992 (in Russian)]

[15] Злобин М.Н., Пермяков Г.П., Немаров А.А., Мецик В.М., Леонов С.Б., Тарабан Н.Т. А.c. 1392722 (1987). Б.И., 1988 [Zlobin M.N., Permiakov G.P., Nemarov A.A., Metsik V.M., Leonov S.B., Taraban N.T. Patent 1392722 (1987). B.I., 1988 (in Russian)]

[16] Классен В.Л. Вопросы теории аэрациии и флотации. М.: Госхимиздат, 1949, 156 с. [Klassen V.L. The theory of aeration and flotation. Moscow, Goskhimizdat, 1949, 156 p. (in Russian)]

[17] Кондратьев В.В., Немчинова Н.В., Иванов Н.А., Ершов В.А., Сысоев И.А. Новые технологические решения по переработке отходов кремниевого и алюминиевого производств. $M e$ таллург, 2013, 5, 92-95 [Kondratiev V.V., Nemchiniva N.V., Ivanov N.A., Ershov V.A., Sysoev I.A. New technological solutions for the recycling of silicon and aluminum plants. Metallurg, 2013, 5, 92-95 (in Russian)]

[18] Ершов В.А., Кондратьев В.В., Сысоев И.А., Мехнин А.О. Извлечение наночастиц углерода из фторированного глинозема при производстве алюминия. Металлург, 2012, 12, 74-78 [Ershov V.A., Kondratiev V.V., Sysoev I.A., Mekhnin A.O. Extraction of carbon nanoparticles of fluorinated alumina for the production of aluminium. Metallurg, 2012, 12, 74-78 (in Russian)]

$$
-669-
$$


[19] Кондратьев В.В., Ершов В.А., Балановский А.Е., Иванчик Н.Н., Карлина А.И. Наноструктуры и алюминиевая промышленность. Вестник Иркутского государственного технического университета, 2015, 8(103), 77-86 [Kondratiev V.V., Ershov V.A., Balanovskii A.E., Ivanchik N.N., Karlina A.I. Nanostructures and aluminum industry. Vestnik Irkutskogo gosudarstvennogo tekhnicheskogo universiteta, 2015, 8(103), 77-86 (in Russian)]

[20] Кондратьев В.В., Иванов Н.А., Ржечицкий Э.П., Сысоев И.А. Перспективы применения нанотехнологий и наноматериалов в горно-металлургической промышленности. Вестник Иркутского государственного технического университета, 2010, 1, 168-174 [Kondratiev V.V., Ivanov N.A., Rzhechitskii A.E., Sysoev I.A. Prospects of application of nanotechnologies and nanomaterials in the mining industry. Vestnik Irkutskogo gosudarstvennogo tekhnicheskogo universiteta, 2010, 1, 168-174 (in Russian)]

[21] Афанасьев А.Д., Иванов Н.А., Ржечицкий А.Э., Кондратьев В.В. Наночастицы углерода в отходах производства алюминия и их модифицирующие свойства. Вестник Иркутского государственного технического университета, 2009, 4, 13-16 [Afanasiev A.D., Ivanov N.A., Rzhechitskii A.E., Kondratiev V.V. Nanoparticles of carbon in the waste of aluminium production and modifying their properties. Vestnik Irkutskogo gosudarstvennogo tekhnicheskogo universiteta, 2009, 4 13-16 (in Russian)]

[22] Кондратьев В.В., Немаров А.А., Иванов Н.А., Карлина А.И., Иванчик Н.Н. Теория и практика процессов флотационного обогащения наноразмерных сред. Иркутск: Изд-во ИрГТУ, 2015, 160 c. [Kondratiev V.V., Nemarov A.A., Ivanov N.A., Karlina A.I., Ivanchik N.N. Theory and practice of the process of flotation enrichment of nanoscale environments. Irkutsk, IrSTU, 2015, 160 c. (in Russian)]

[23] Ржечицкий А.Э., Ржечицкий Э.П., Кондратьев В.В., Иванов Н.А. Способ выделения углеродных наночастии: пат. 2504514 Рос. Федерации: МПК С01В 31/02, В82B 3/00, В82Y 40/00; патентообладатель ФГБОУ ВПО “Иркутский государственный технический университет”. № 2011152263/05; заявл. 22.12.2011; опубл. 20.01.2014, Бюл. № 2 [Rzhechitskii A.E., Rzhechitskii E.P., Kondratiev V.V., Ivanov N.A. A method of separating carbon nanoparticles. Patent Russian Federation]

[24] Кондратьев В.В., Немаров А.А., Ржечицкий А.Э., Иванов Н.А., Лебедев Н.В. Способ извлечения наноразмерных частии из техногенных отходов производства флотацией: пат. Рос. Федерации МПК B03D 1/02, C01B 31/00, C01B 33/12; патентообладатель ФГБОУ ВПО «Иркутский государственный технический университет». № 2012106061/05; заявл. 20.02.2012; опубл. 10.12.2013. Бюл. № 34. [Kondratiev V.V., Nemarov A.A., Rzhechitskii A.E., Ivanov N.A., Lebedev N.V. A method of extracting nano particles from industrial waste production by flotation. Patent Russian Federation] 